TP Periodica Polytechnica

58(2), pp. 81-91, 2014

DOI: $10.3311 /$ PPch.2179

Creative Commons Attribution (i)

RESEARCH ARTICLE

\section{Theoretical and Experimental Approaches of Liquid Entry Pressure Determination in Membrane Distillation Processes}

\author{
Gábor Rácz ${ }^{1 *}$ / Steffen Kerker $^{2} /$ Zoltán Kovács ${ }^{1,2} /$ Gyula Vatai ${ }^{1}$ \\ Mehrdad Ebrahimi ${ }^{2} /$ Peter Czermak ${ }^{2,3}$ \\ RECEIVED 27 JUNE 2013; ACCEPTED AFTER REVISION 31 JANUARY 2014
}

\begin{abstract}
Membrane distillation (MD) is a thermally driven separation process that employs a hydrophobic membrane as a barrier for the liquid phase, allowing only vapor phase to pass through the membrane pores. Wetting of membrane pores by liquid streams (i.e. the loss of hydrophobic characteristics of membranes) is a crucial issue in MD treatment. This paper is organized into two parts. The first part provides an overview of the theoretical background of wetting phenomenon and guides the reader through the experimental techniques presented in the literature for determining liquid entry pressure (LEP) of MD membranes. In the second part, we provide experimentally measured data on LEP values of some commercially available hollow-fiber and flat-sheet membranes tested in our lab using different MD configurations. The LEP ${ }_{w}$ value of the MD $020 \mathrm{CP} 2 \mathrm{~N}$ hollow-fiber membrane (Microdyn-Nadir GmbH, Wiesbaden, Germany) made of PP is found to be 0.97 bar using direct-contact membrane distillation (DCMD) configuration. The $L E P_{w}$ value of the Durapore $^{T M}$ GVPH flat sheet membrane (Merck Millipore Inc., Billerica, USA) made of PVDF is found to be $2.37 \pm 0.025 \mathrm{bar}$ using static measurement technique and 1.90 bar using vacuum $M D$ configuration. We also show that wetted membranes can be successfully regenerated by soaking them in ethanol and removing ethanol with evaporation at elevated temperatures. A novel concept of regeneration procedures applying vacuum have developed and have been proved to be effective for the tested flat sheet modules, however, failed on recovering the hydrophobic characteristics of the PP membrane in the hollow-fiber module.
\end{abstract}

\section{Keywords}

liquid entry pressure $\cdot$ membrane distillation $\cdot$ microporous hydrophobic membrane $\cdot$ hollow fiber module flat sheet module $\cdot$ wetting phenomena $\cdot$ regeneration of wetted pores

\footnotetext{
${ }^{1}$ Department of Food Engineering, Corvinus University of Budapest, Budapest, Hungary

${ }^{2}$ Institute of Bioprocess Engineering and Pharmaceutical Technology, University of Applied Sciences Mittelhessen, Giessen, Germany ${ }^{3}$ Department of Chemical Engineering, Kansas State University, Manhattan *Corresponding author, e-mail: gabor.racz2@uni-corvinus.hu
}

\section{Introduction}

Membrane distillation (MD) is a thermally driven separation technique using microporous hydrophobic membranes and performing on the principles of vapor-liquid equilibrium under different configurations. In this process, only volatile compounds (mainly water) of the feed stream evaporate at the membrane pore entrance, cross the membrane pores in vapor phase to finally be either condensed or removed as a vapor from a membrane module. The hydrophobic nature of the membrane prevents the pores from wetting by capillary forces. MD is known as a promising technology for many applications such as desalting seawater, brackish water, highly saline water $[1,2]$, and removing organic compounds and heavy metals from aqueous solutions [3, 4]. MD has also been used to manage waste water such as radioactive waste waters, oily waste waters [5], where the product could be safely discharged to the environment or the waste streams could be reused in an appropriate industrial activity. In biotechnology and food processing applications, MD has also been found as a promising tool, for instance, for removing ethanol and other metabolites from fermentation broths [6], for gentle concentration of valuable compounds in fruit juices [7], and in herb extract such as Ginseng [8].

MD has many attractive features as compared to conventional separation processes. Low operating temperatures $\left(\sim 30-70^{\circ} \mathrm{C}\right)$ is one of them since the feed is not necessarily heated up to the boiling point like in thermal distillation. Thus, MD may advantageously utilize alternative energy sources, such as solar energy, geothermal energy, waste heats from power plant, etc. [9]. Compared with pressure driven membrane filtration processes such as nanofiltration or reverse osmosis, lower operating pressure translates to lower equipment costs and increased process safety. It is worth highlighting that membrane fouling in MD seems to be less of a problem for many applications than that in pressure-driven filtration processes [10].

MD is, however, attended by some drawbacks. Compared to reverse osmosis, MD is known to have a lower permeate flux, and the susceptibility of permeate flux to processing conditions, particularly to temperature and concentration, is considerably high. Also, the trapped air within the membrane pores 
introduces a further mass transfer resistance, which limits the MD permeate flux. Moreover, the heat loss by conduction through the membrane material can be quite large, especially in direct contact membrane distillation. Until now, little efforts have been made in manufacturing membranes and modules specifically designed for MD, however, the number of publications on the applicability of MD for various separation tasks increases rapidly. In MD practice, it is very common to use commercially available microporous hydrophobic membranes originally manufactured for microfiltration purposes. It should be also noted that there are some recent investigations aiming at developing new MD membrane materials and modifying microfiltration membranes in order to obtain improved non-wettability characteristics of membrane surfaces that may find MD applications in the future. These include, for example, migrating fluorinated surface modifying macromolecules to the top of the membrane surface [11], $\mathrm{CF}_{4}$ plasma surface modification [12], and creating superomniphobic characteristics of nanotube-structured $\mathrm{TiO}_{2}$ surfaces [13].

Wetting of membrane pores by the liquid streams is a crucial issue in MD treatment. If membrane pores are wetted by the feed or permeate stream, liquid is able to penetrate into the pores thereby the membrane cannot function as a MD membrane anymore. In this case, the wetted membrane behaves in a fashion as a conventional microfiltration membrane.

This study presents an overview of the theoretical background of wetting phenomenon and experimental determination methods of liquid entry pressure (LEP) in MD processes based on the relevant open literature. Furthermore, novel LEP measurements and regeneration tests using a commercial hollow fiber module in direct contact membrane distillation (DCMD) and a flat sheet membrane in vacuum membrane distillation (VMD) configuration have been carried out.

\section{Theory}

In $\mathrm{MD}$, vapor pressure difference, as a result of temperature gradient, transports only volatile molecules from the high temperature feed aqueous stream across the microporous hydrophobic membrane to produce purified condensed liquid on the low temperature liquid stream distillate side. DCMD, which condenses the vapor directly into a cold liquid stream, is the most common configuration for MD. Figure 1. shows the liquid/vapor interfaces at the entrance of the pores formed in DCMD configuration.

The main requirement in this process is that the membrane is not wetted by liquid mixtures, thus, the hydrophobicity of the membrane is a decisive factor to make the MD process viable. Mostly hydrophobic polymers, such as polytertaflourethylene (PTFE), polyvinylideneflouride (PVDF), polypropylene (PP) and polyethylene (PE) membranes are used in MD treatment.

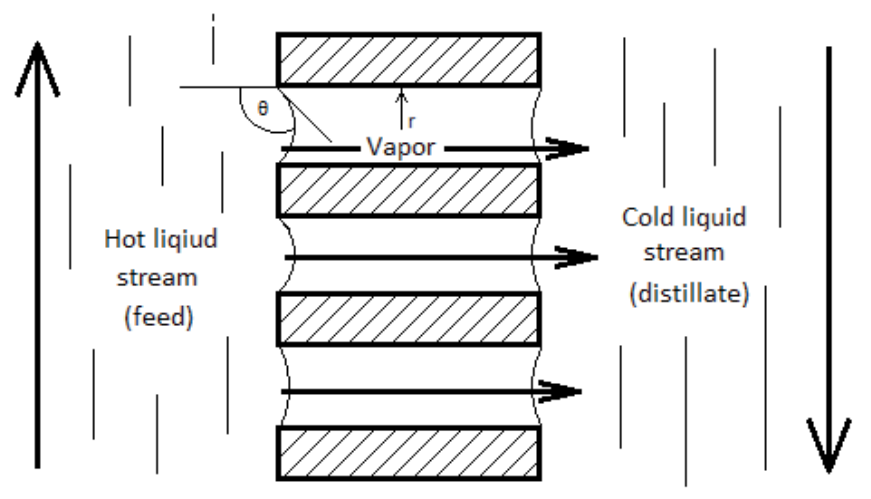

Fig. 1. Direct contact membrane distillation.

\subsection{Theoretical description of liquid entry pressure}

The pressure difference between liquid-vapor interfaces is expressed according to the Laplace-Young equation. Liquid entry pressure (LEP) is the minimum value of hydrostatic pressure difference which the feed liquid penetrates into the largest pores of the membrane. This critical pressure difference is related to the interfacial tension, the contact angle of the liquid at the pore entrance, and the size and shape of membrane pores.

Franken et al. [14] has suggested a model to determine LEP value based on Laplace-Young equation:

$$
L E P_{W}=\frac{-2 B_{\gamma L} \cos \theta}{r_{\max }}
$$

where $\mathrm{LEP}_{\mathrm{w}}$ is the liquid entry pressure of pure water in $\mathrm{Pa}, \mathrm{B}$ is a dimensionless geometrical factor which includes the irregularities of the pores ( $B=1$ for assumed cylindrical pores), $\gamma_{L}$ is the liquid surface tension in $\mathrm{N} \mathrm{m}^{-1}, \cos \theta$ is the contact angel in degree, $r_{\max }$ is the maximal pore (non-closed) radius in $\mathrm{m}$.

Even though do not explicitly occur in Eq. (1), operating temperature and process solution composition, can have a significant impact on liquid-solid contact angle and liquid surface tension. These effects should not be overlooked when selecting a membrane.

Another theoretical model has been published by Kim et al. [15]. They have studied a model for membranes with noncylindrical pores. They supposed that the membrane structure is a reticular fiber structure, and deduced an equation similar to the Laplace-Young equation:

$$
\Delta P=-\frac{2 \gamma L}{\gamma} \cos \theta_{e f}
$$

where $\Delta \mathrm{P}$ is the pressure difference across the interfaces, $\gamma_{\mathrm{L}}$ is the liquid-vapor surface tension, $\theta_{\text {ef }}$ is the effective contact angle, and $\mathrm{r}$ is the pore radius, which is defined as half of the mean distance betweenfibers. $\theta_{\text {ef }}$ can be expressed in terms of contactangle, $\theta$, and always $\theta_{\text {ef }}>\theta$.

If hydrostatic pressure difference exceeds $\mathrm{LEP}_{\text {w }}$, wetting occurs. Zha et al. [16] have introduced that if the geometry of the pore is axially irregular, a structure angle, $\alpha$, may be 
defined. Figure 2. explains clearly that this $\alpha$ angle can be measured in between a pore wall element and the normal to the membrane surface in the axial direction. The force due to the pressure difference across the interfaces will be equal to the surface force, so that, the pressure difference between the interfaces can be written as:

$$
\Delta P=-\frac{2 \gamma L}{\gamma} \frac{\cos \left(\theta_{A}-\alpha\right)}{1+\frac{R}{\gamma}(1-\cos \alpha)}
$$

where $\Delta \mathrm{P}$ is the pressure difference between the liquid-vapor interfaces, $\mathrm{r}$ is the mean pore radius, $\theta_{\mathrm{A}}$ is the advancing contact angle, $\mathrm{R}$ is the mean curvature radius of pore wall element, and $\alpha$ is the average $\alpha$ since its value may change along the pore. The parameter $\mathrm{R} / \mathrm{r}$ is the measure of the relative curvature of the membrane pore structure. Larger values of $\mathrm{R} / \mathrm{r}$ correspond to rounder edged pores.

The surface tension of aqueous solutions of inorganic salts is greater than that of pure water $\left(72 \mathrm{mNm}^{-1}\right)$, thus, they have a limited ability to wet membrane pores. However, surface tension, $\gamma_{L}$, decreases sharply when solutions contain organic solutes or surfactants. If the concentration of surfactants becomes sufficiently high to exceed a certain critical value, a spontaneous wetting of membrane occurs [17]. Wetting can be directly measured by contact angle. Contact angle is expressed as interaction between the liquid phase and the solid membrane surface. This value has to be larger than $90^{\circ}$; recommended

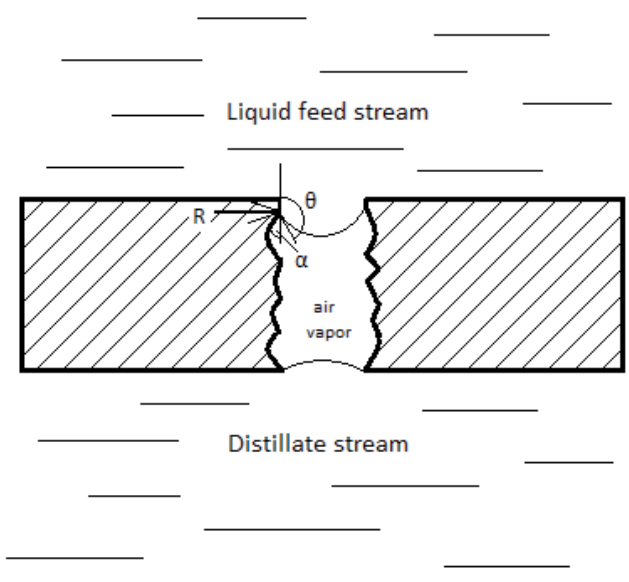

Fig. 2. Schematic representation of pore structure and structure angle $\alpha$ based on Zha et al [16].

value is around $130^{\circ}$. In extreme cases it is able to reach value of $180^{\circ}$ [18]. In general, smaller pore size, greater contact angle and surface tension increase the value of LEP.

The wetting of the pores leads to reduced product quality, thus, it is advantageous to use membranes with $\operatorname{LEP}_{\mathrm{W}}$ value as high as possible. The theoretical value of $\mathrm{LEP}_{\mathrm{W}}$ is $1.85 \mathrm{bar}$ considering pure water, cylindrical pores $(B=1), 130^{\circ}$ contact angle, and $1 \mu \mathrm{m}$ pore diameter [10]. In practice, the experimentally measured $\mathrm{LEP}_{\mathrm{W}}$ values of flat-sheet membranes are in between 0.48 -4.63 bar. Table 1. summarizes the LEP $_{w}$ values of commercially available microfiltration membranes.

Tab. 1. $\mathrm{LEP}_{\mathrm{w}}$ values of commercially available of hydrophobic membrane modules

\begin{tabular}{|c|c|c|c|c|c|c|}
\hline Manufacturer & Membrane & Material & Membrane/module & $d_{p}, \mu m$ & LEP $_{w}$, bar & Reference \\
\hline $\begin{array}{c}\text { Pall Gelman (Port } \\
\text { Washington, NY, USA) }\end{array}$ & TF200 & $\begin{array}{l}\text { PTFE/ } \\
\text { PPa }^{a}\end{array}$ & $\begin{array}{l}\text { Supported flat-sheet } \\
\text { membrane }\end{array}$ & 0.20 & $2.82 / 2.76 \pm 0.09$ & $\begin{array}{l}\text { Membrane data sheet by Pall } \\
\text { Gelman/ Measured value [19] }\end{array}$ \\
\hline $\begin{array}{c}\text { Pall Gelman (Port } \\
\text { Washington, NY, USA) }\end{array}$ & TF450 & $\begin{array}{l}\text { PTFE/ } \\
\text { PPa }\end{array}$ & $\begin{array}{l}\text { Supported flat-sheet } \\
\text { membrane }\end{array}$ & 0.45 & 1.38 & $\begin{array}{l}\text { Membrane data sheet by Pall } \\
\text { Gelman }\end{array}$ \\
\hline $\begin{array}{c}\text { Pall Gelman (Port } \\
\text { Washington, NY, USA) }\end{array}$ & TF1000 & $\begin{array}{l}\text { PTFE/ } \\
\text { PPa }^{a}\end{array}$ & $\begin{array}{l}\text { Supported flat-sheet } \\
\text { membrane }\end{array}$ & 1.00 & 0.48 & $\begin{array}{l}\text { Membrane data sheet by Pall } \\
\text { Gelman }\end{array}$ \\
\hline $\begin{array}{c}\text { Gore Inc. } \\
\text { (Newark, USA) }\end{array}$ & Gore (PT20) & PTFE & $\begin{array}{l}\text { Flat-sheet } \\
\text { membrane }\end{array}$ & 0.2 & $3.68 \pm 0.01$ & Measured value [20] \\
\hline $\begin{array}{c}\text { Gore Inc. } \\
\text { (Newark, USA) }\end{array}$ & Gore (PT45) & PTFE & $\begin{array}{l}\text { Flat-sheet } \\
\text { membrane }\end{array}$ & 0.45 & $2.88 \pm 0.01$ & Measured value [20] \\
\hline $\begin{array}{c}\text { Gore Inc. } \\
\text { (Newark, USA) }\end{array}$ & Gore (PTS20) & $\begin{array}{l}\text { PTFE/ } \\
\text { PPa }^{a}\end{array}$ & $\begin{array}{l}\text { Supported flat-sheet } \\
\text { membrane }\end{array}$ & 0.2 & 4.63 & Measured value [20] \\
\hline $\begin{array}{l}\text { Microdyn- Nadir GmbH } \\
\text { (Wiesbaden, Germany) }\end{array}$ & MD020CP2N & PP & Hollow fiber module & 0.2 & 1.40 & $\begin{array}{l}\text { Membrane data sheet by } \\
\text { Microdyn-Nadir }\end{array}$ \\
\hline $\begin{array}{l}\text { Merck Millipore Inc. } \\
\text { (Billerica, USA) }\end{array}$ & GVHP/Durapore & PVDF & $\begin{array}{l}\text { Flat-sheet memb- } \\
\text { rane }\end{array}$ & 0.22 & $2.04 / 2.29 \pm 0.03$ & $\begin{array}{l}\text { Membrane data sheet by Merck } \\
\text { Millipore/ Measured value [20] }\end{array}$ \\
\hline $\begin{array}{l}\text { Merck Millipore Inc. } \\
\text { (Billerica, USA) }\end{array}$ & HVHP/Durapore & PVDF & $\begin{array}{l}\text { Flat-sheet } \\
\text { membrane }\end{array}$ & 0.45 & $\begin{array}{c}1.05 / 1.10 \pm \\
0.04\end{array}$ & $\begin{array}{c}\text { Membrane data sheet by Merck } \\
\text { Millipore/ [20] }\end{array}$ \\
\hline $\begin{array}{l}\text { Merck Millipore Inc. } \\
\text { (Billerica, USA) }\end{array}$ & FGLP & $\begin{array}{l}\text { PTFE/ } \\
\text { PE }^{a}\end{array}$ & $\begin{array}{l}\text { Supported flat-sheet } \\
\text { membrane }\end{array}$ & 0.20 & 2.80 & $\begin{array}{l}\text { Membrane data sheet by Merck } \\
\text { Millipore }\end{array}$ \\
\hline $\begin{array}{l}\text { Merck Millipore Inc. } \\
\text { (Billerica, USA) }\end{array}$ & FHLP & $\begin{array}{l}\text { PTFE/ } \\
\text { PE }^{a}\end{array}$ & $\begin{array}{l}\text { Supported flat-sheet } \\
\text { membrane }\end{array}$ & 0.50 & 1.24 & $\begin{array}{l}\text { Membrane data sheet by Merck } \\
\text { Millipore }\end{array}$ \\
\hline
\end{tabular}

${ }^{a}$ Flat sheet polytetrafluoroethylene, PTFE, membranes supported by polypropylene, PP, or polyethylene, PE 
If liquid penetrates into the pores, the selectivity of the membrane changes. In this case, the process operates like in microfiltration because the trapped air and vapor are removed from the pores. Wetting phenomenon is illustrated in Figure 3., which shows the effect of increasing, and then subsequently decreasing hydrostatic pressure on the feed side of a MD membrane. First, the pressure is increased no water can flow through the membrane until $\mathrm{LEP}_{\mathrm{w}}$ is exceeded (1). At this point liquid begins to penetrate the largest pores and is able to pass through the membrane. As the pressure is increased further, more and more pores become flooded and the liquid flux increases accordingly (2). Once all the pores have become flooded, the liquid flux across the membrane obeys Darcy's law, and decreasing the pressure results in a linear decrease in flux (3) [10].

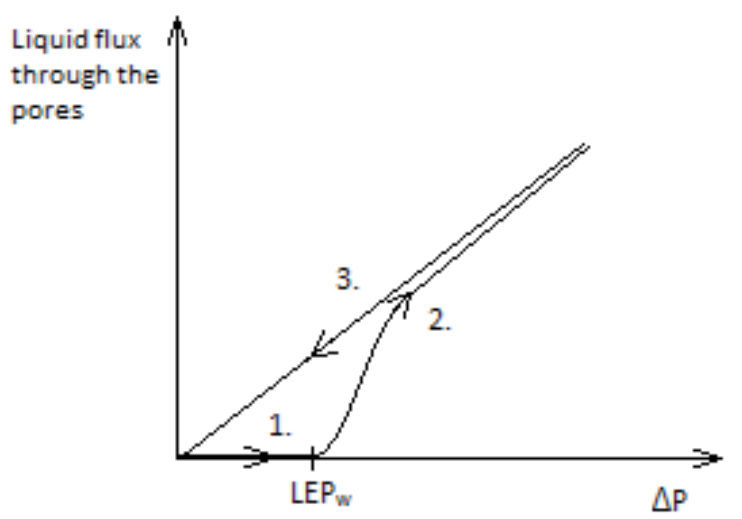

Fig. 3. Hysteresis of MD membrane wetting based on Lawson and Lloyd [10].

\subsection{Experimental determination of LEP}

Up to now, only a few methods have been published for determining $\mathrm{LEP}_{\mathrm{w}}$. Most of them are based on a simple method, first presented by Smolder et. al [21]. Figure 4. illustrates the sketch of $\mathrm{LEP}_{\mathrm{w}}$ measurement for a flat sheet membrane by Khayet and Matsuuura [22]. The examined membrane lies between an upper and a lower chamber in the static testing cell. The upper chamber is filled up with distilled water, and the lower is connected to a digital flow meter. The upper chamber is connected directly to an air cylinder which generates pressure. First, a low pressure of air is applied $(30 \mathrm{kPa})$ at least for 10 minutes. Then, the pressure is increased in the upper chamber in small steps $(0.68 \mathrm{kPa})$. The $\mathrm{LEP}_{\mathrm{w}}$ value is found, when a continuous flow can be detected in the lower chamber with the digital flow meter.

A similar method has been presented by Garcia-Payo et al. [17]. In their investigations, a small capillary with $1 \mathrm{~mm}$ of inner diameter is connected to the lower chamber. This capillary is filled up with water. In this capillary a stagnant meniscus is observed without applied pressure. The hydrostatic pressure

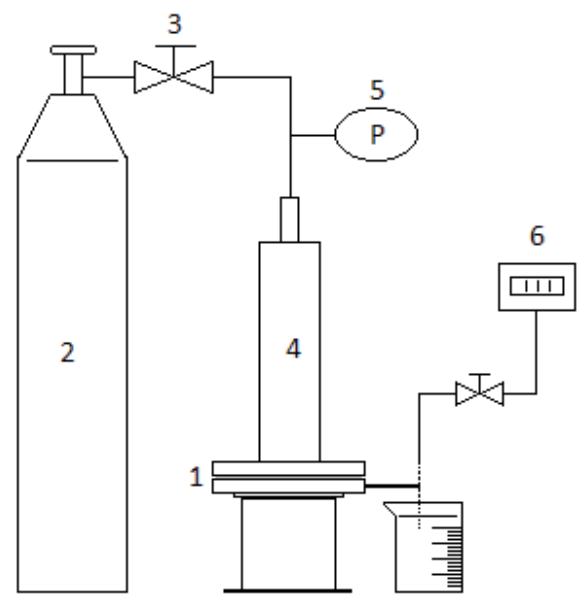

Fig. 4. Measurement of liquid entry pressure of pure water (adopted from Khayet and Matsuura [22]) (1. flat-sheet membrane, 2. air cylinder, 3. valve, 4. static testing cell, 5. pressure gauge, 6 . digital flow meter).

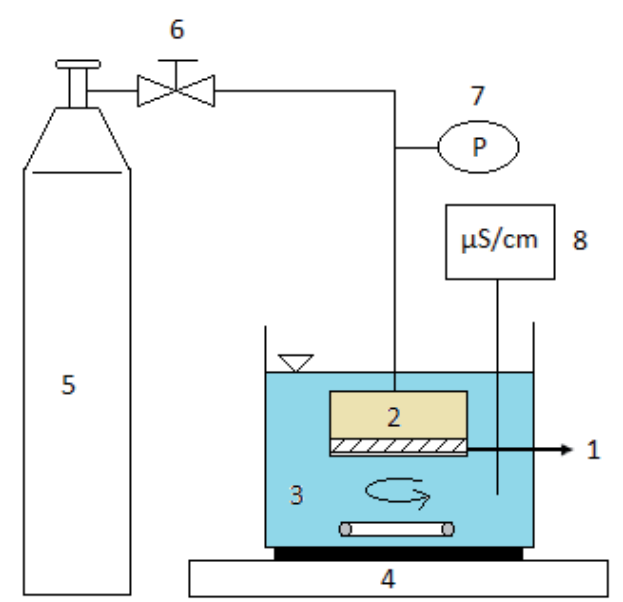

Fig. 5. Method to determine liquid entry pressure for $\mathrm{NaCl}$ solutions (adopted from He et al. 2011 [23]) (1. membrane, 2. $20 \mathrm{~m} / \mathrm{m} \% \mathrm{NaCl}$ solution, 3. water bath, 4. magnetic stirrer, $5 . \mathrm{N}_{2}$ cylinder 6 . valve, 7. pressure gauge, 8 . conductometer).

is increased in small steps in the upper chamber during the experiment. When pressure exceeds the "break-through value" the stagnant meniscus moves up. This movement is measured by cathetometer, and $\mathrm{LEP}_{\mathrm{w}}$ value can be determined.

Figure 5. shows the method introduced by He et al. to determine LEP [23].

The membrane cell is filled up with $20 \mathrm{~m} / \mathrm{m} \% \mathrm{NaCl}$ solution and submerged in a water bath. $\mathrm{N}_{2}$ gas is used to increase the hydrostatic pressure in the membrane cell similarly to the previous methods. A magnetic stirrer is used to ensure an appropriate mixing in the water bath. When the pressure reaches the LEP value in the membrane cell, salty water is able to penetrate through the pores, and the conductivity of water bath increases rapidly. A conductometer is used to determine the change in conductivity in the water bath caused by the presence of salts. The sudden change in conductivity can then be related to the LEP value. 


\subsection{Regeneration of the wetted membranes}

If the hydraulic pressure, for some reasons, exceeds the respective LEP value of the membrane, the membrane pores become wetted. Thus, MD can no longer be performed [24,10], and the membrane obeys Darcy's law. In order to recover MD properties, the membrane has to be first regenerated, i.e. liquid water has to be removed from the pores, and the liquidvapor interfaces have to be restored. Little attention has been devoted yet to such regeneration issues in the open literature. On lab-scale, it is common to dismount the lab rig and to let the flat-sheets completely dry out at elevated temperatures within longer periods of time. It is also recommended to filtrate ethanol through the wetted membrane prior to drying in order to remove water rests from the pores that otherwise can be hardly eliminated by drying procedure. Obviously, such procedures applied in laboratory-scale investigations have limited applicability at larger scale, especially for complex module geometries. To the best of our knowledge, no standard procedures are provided on how wetted MD modules can be regenerated in practice.

\section{Experimental}

\subsection{Determination of $\operatorname{LEP}_{\mathrm{w}}$ value}

LEP $_{w}$ and LEP values are crucial limiting factors in MD process design. In scale-up, the maximal pressure-drop over the modules should not exceed LEP. In our study, the following methods were performed to experimentally determine the $\mathrm{LEP}_{w}$ value of a polypropylene (PP) hollow fiber and PVDF flat sheet membranes.

\subsubsection{Determination of LEP $w$ value and hysteresis curve of wetting for hollow fiber module}

MD 020 CP 2N hollow fiber module (Microdyn-Nadir GmbH, Wiesbaden, Germany) was examined. This module contained 40 pieces of hydrophobic porous membrane fibers made of PP. The nominal pore size of the membrane was $0.2 \mu \mathrm{m}$, and the useful membrane area was $0.1 \mathrm{~m}^{2}$. The internal and the external capillary diameter were $1.8 \mathrm{~mm}$ and $2.6 \mathrm{~mm}$, respectively. Temperature was kept at $25^{\circ} \mathrm{C}$. Volumetric flow-rates were fixed at laminar flow condition with $36 \mathrm{~L} / \mathrm{h}$ volumetric flowrate. It resulted flowing condition with $\mathrm{Re}_{\text {Feed }}=260$ on the feed side and $\operatorname{Re}_{\text {Permeate }}=170$ on the permeate side. It was presumed that this slight difference had no significant influence on the measured LEP values. The $\mathrm{LEP}_{w}$ tests were performed using the experimental set-up is presented in Figure 6.

The set-up was similar to a usual direct contact membrane distillation plant. Feed and distillate streams flew co-currently. Feed stream was circulated in the fibers. A gear pump (Ismatec MCP-Z, Switzerland) was used for the feed stream circulation, and a peristaltic pump (Watson-Marlow 501U, UK) was used at the distillate stream. For increasing the pressure in the fibers to reach $\mathrm{LEP}_{\mathrm{w}}$ value, a pressure regulator was employed at the outlet of the feed side channels. The feed stream contained low amount of sodium chloride for the determination of LEP $_{w}$ - conductivity of the feed stream was $0.36 \mathrm{mScm}^{-1}$ at $24.7^{\circ} \mathrm{C}$ measured by Hanna HI 99301 EC meter (Hanna instruments, Woonsocket, Rhode Island, USA). It was assumed that there is no significant effect of salt concentration on $\mathrm{LEP}_{\mathrm{w}}$ value in this low salt concentration range. Distilled water was circulated in

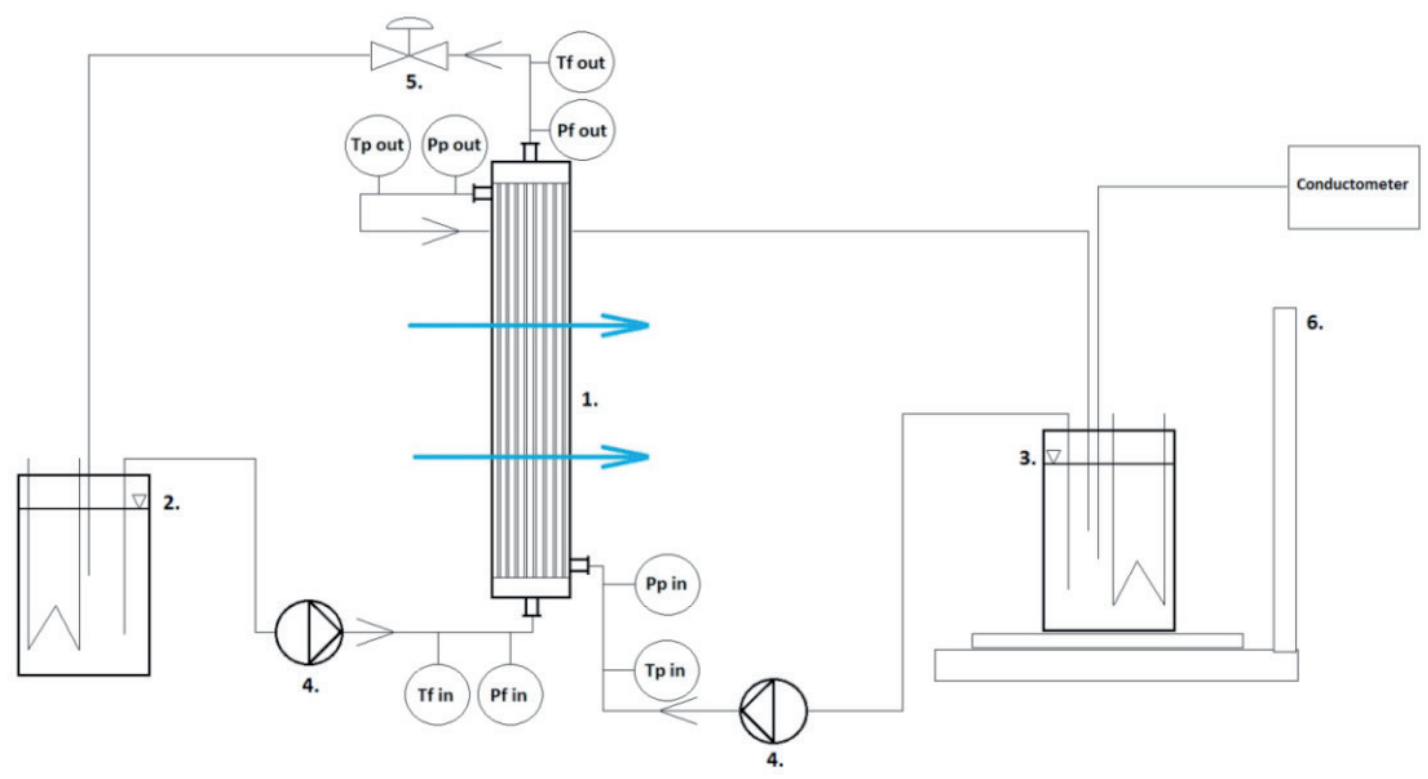

Fig. 6. Schematics of liquid entry measurement of pure water in case of MD $020 \mathrm{CP} 2 \mathrm{~N}$ hollow fiber module (Microdyn-Nadir GmbH, Wiesbaden, Germany) (1. hollow fiber membrane module, 2. feed container, 3. permeate container, 4. peristaltic pumps, 5. pressure regulator, 6. digital balance). 
the distillate side, i.e. the shell side of the module, with less than $0.01 \mathrm{mScm}^{-1}$ at $25.1^{\circ} \mathrm{C}$ (under the detection limit of the conductometer). A digital balance was used for the determination of liquid flux measuring hysteresis curve. The temperature and pressure sensors (Wika GmbH, Germany) as well as the digital balance (Mettler-Toledo, Switzerland) were connected to Lab-manager (HiTech Zang GmbH, Germany) interface and the measured values were monitored by LabVision (HiTech Zang GmbH, Germany).

The experiment was performed in two consecutive steps: first identifying the $\mathrm{LEP}_{\mathrm{W}}$ value, and then, determining the hysteresis curve. Both streams were recirculated during the experiment. The transmembrane pressure was increased stepwise in every five minutes until $\mathrm{LEP}_{\mathrm{w}}$ value was reached. In the moment when LEP $_{W}$ was reached, a rapid increase was observed in the conductivity value of the distillate stream and in the total mass of the distillate. Pressure, temperature, and mass readings were recorded by LabVision monitor system.

\subsubsection{Determination of $\operatorname{LEP}_{\mathrm{w}}$ for}

\section{flat sheet membrane - static method}

Durapore $^{\mathrm{TM}} \mathrm{GVPH}$ flat sheet membrane (Merck Millipore Inc., Billerica, USA) was also examined. The membrane material is made of PVDF. The nominal pore size of the membrane is $0.22 \mu \mathrm{m}$, and the active membrane area is $0.00444 \mathrm{~m}^{2}$. The measurements were carried out at room temperature $\left(21-24^{\circ} \mathrm{C}\right)$. The controlling system was the same as that described in Sect. 3.1.1. The LEP experiments were performed using the experimental set-up presented in Figure 7. The upper part of the membrane module was filled up with distilled water to be in direct contact with the examined membrane. The outlet of the upper part was closed with a valve and a stagnant water layer formed at the top of the membrane. First, a low pressure was applied ( 0.2 bar) for 10 minutes using compressed air as shown in Figure 7. Then, the pressure of the upper part was increased in every 5 minutes with 0.1 bar until the $\mathrm{LEP}_{\mathrm{w}}$ was reached. At this moment, water started to penetrate the pores and press out the air trapped there. The released air flew through the downer space tube of the module and bubbled through the container underneath filled with distilled water. It was then followed by a moving meniscus in the permeate tube until all liquid from upper part passed through the membrane.

\subsubsection{Determination of $\operatorname{LEP}_{w}$ and hysteresis curve of wetting in case of flat sheet membrane - dynamic method}

Figure 8. illustrates the method of the dynamic measurement. The flat sheet module described in Sect. 3.1.2. was used here. The feed liquid was recirculated with volumetric flow rate $35 \mathrm{~L} / \mathrm{h}$ which resulted flow condition with Reynolds number of 500. The feed side hydrostatic pressure was increased stepwise ( 0.2 bar) in every five minutes until the feed side pressure was

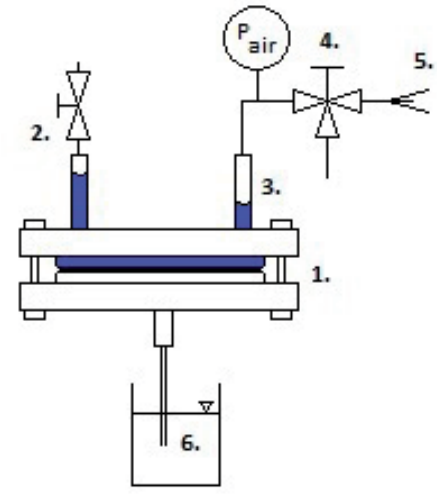

Fig. 7. Schematics of liquid entry pressure measurement of pure water of Durapore ${ }^{\mathrm{TM}} \mathrm{GVPH}$ flat sheet membrane (Merck Millipore Inc., Billerica, USA) using static method (1. flat sheet membrane module, 2. valve, 3. feed side of the membrane module filled with distilled water, 4 . valve for the air stream, 5 . inlet of the air stream, 6. container filled with distilled water).

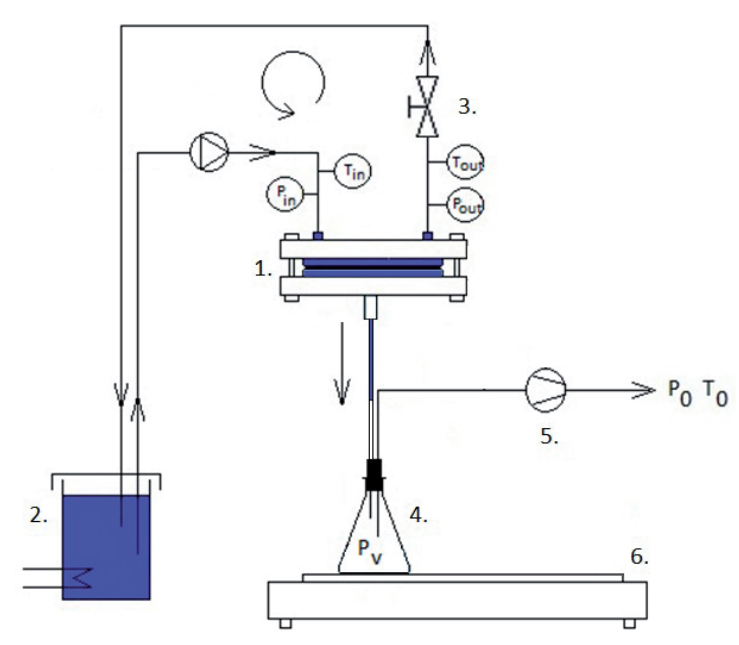

Fig. 8. Schematics of dynamic liquid entry pressure measurement in case of DuraporeTM GVPH flat sheet membrane (Merck Millipore Inc., Billerica, USA) using dynamic method (1. module, 2. feed pure water, 3. valve , 4. permeate flask, 5. vacuum pump, 6. digital balance).

reached 1 bar, the maximum set which could be generated on feed side hydrostatic pressure in this set-up. Thereafter on the permeate side a vacuum was applied and increased stepwise the hydrostatic pressure difference to finally reach the LEP. In this moment a moving liquid meniscus could be noticed in the permeate side tube.

Once $\mathrm{LEP}_{\mathrm{W}}$ was reached, the filtration performance of the membrane could be tested. The permeate flux of the wetted membrane was recorded at different pressures by using the balance placed under the permeate reservoir.

\subsection{Regeneration of the wetted membrane}

Two different types of regeneration procedures were applied to the wetted MD $020 \mathrm{CP} 2 \mathrm{~N}$ hollow fiber and Durapore ${ }^{\mathrm{TM}}$ GVPH flat sheet membranes as explained below: a frequently used drying procedure applying elevated temperature and a 
novel method developed by our team which uses vacuum to evaporate the residues of the liquid from the wetted pores. Both of the regeneration techniques were carried out after LEP $_{w}$ measurements, i.e. after pores were flooded by the feed.

\subsubsection{Regeneration based on solvent evaporation at elevated temperature}

Regeneration of both membranes (MD 020 CP 2N and Durapore $^{T M}$ GVPH) using hot air stream was investigated. The effect of an additional ethanol treatment on success of regeneration was also investigated.

In case of applying ethanol, prior to drying in the oven, ethanol (96 v/v\%) was first filtrated through the membrane (30 min, 0.3 bar in total recycle mode), then membranes were stored further in ethanol (96 v/v\%) for one day. After it, the membranes were dried out in a laboratory oven at $50^{\circ} \mathrm{C}$ in 48 hours. In case of Durapore ${ }^{\mathrm{TM}} \mathrm{GVPH}$, the flat sheet module was first disassembled and the membrane discs were then placed in the oven. In case of MD $020 \mathrm{CP} 2 \mathrm{~N}$, the complete module was placed in the oven. After solvent evaporation, the flat-sheet module (Durapo$\left.\mathrm{re}^{\mathrm{TM}} \mathrm{GVPH}\right)$ was tested in VMD configuration $\left(\mathrm{T}_{\mathrm{Feed}}=40^{\circ} \mathrm{C}\right.$, $\operatorname{Re}_{\text {Feed }}=500, \mathrm{P}_{\text {vacuum }}=60 \mathrm{mbar}$ ) and the hollow-fiber module in DCMD configuration $\left(\mathrm{T}_{\text {feed }}=25^{\circ} \mathrm{C}, \mathrm{Re}_{\text {Feed }}=260\right.$, and $\operatorname{Re}_{\text {Permeate }}=170$ ) using water with low salt concentration $\left(0.36 \mathrm{mScm}^{-1}\right.$ at $\left.24.7^{\circ} \mathrm{C}\right)$ as feed. Conductivity of permeate was finally determined and if this value was less than $0.01 \mathrm{mScm}-1$, (detection limit of the conductometer) the regeneration process was succeed.

3.

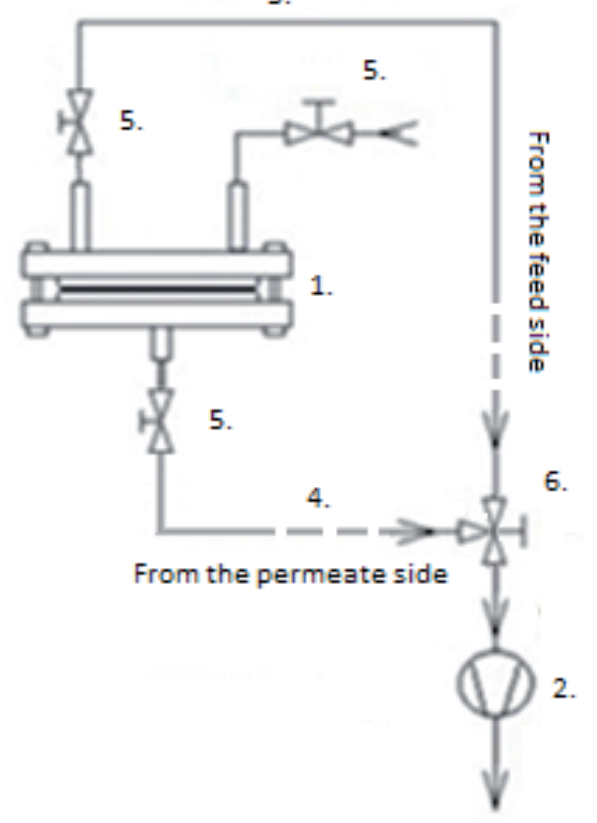

Fig. 9. Regeneration procedure applying vacuum (1. wetted membrane, 2. vacuum pump, 3. vacuum applying at the feed side, 4 . vacuum applying at the permeate side, 5 . valves for controlling the flow rate, 6 . switch between feed or permeate side vacuum).

\subsubsection{Regeneration procedure using vacuum}

Tests were performed with and without ethanol treatment prior to applying vacuum. Ethanol treatment was performed in two steps. First, ethanol ( $96 \mathrm{v} / \mathrm{v} \%$ ) was filtrated through the membranes (30 min, 0.3 bar in total recycle mode). Then, wetted membranes were stored in ethanol $(96 \mathrm{v} / \mathrm{v} \%)$ for one day.

The effect of vacuum applied at the feed side or the distillate side as well as their combination was investigated. The regeneration tests were performed with a laboratory vacuum pump using the set-up shown in Figure 9. The regeneration of both hollow-fiber and flat-sheet module was carried out using this set-up. The experimental plan of the regeneration procedure using vacuum is presented in Figure 10. All tests were performed at ambient temperature and $\mathrm{P}_{\text {vacuum }}=150$ mbar downstream pressure. First, an air stream was applied to drive out water from the modules. Then, suction with a vacuum pump was applied either from the distillate-side or from the feedside (or both). After vacuum treatment, the flat-sheet module (Durapore ${ }^{\mathrm{TM}} \mathrm{GVPH}$ ) was tested in VMD configuration $\left(\mathrm{T}_{\text {Feed }}=40^{\circ} \mathrm{C}, \mathrm{Re}_{\mathrm{Feed}}=500, \mathrm{P}_{\text {vacuum }}=60 \mathrm{mbar}\right)$ and the hollow-fiber module in DCMD configuration $\left(\mathrm{T}_{\text {Feed }}=25^{\circ} \mathrm{C}, \mathrm{Re}_{\text {Feed }}=260\right.$, and $\left.\operatorname{Re}_{\text {Permeate }}=170\right)$ using water with low salt concentration $(0.36$ $\mathrm{mScm}^{-1}$ at $24.7^{\circ} \mathrm{C}$ ) as feed. If wetting occurred, the regeneration procedure was repeated by increasing the suction time with 5 minutes. Conductivity of permeate was measured and if this value was less than $0.01 \mathrm{mScm}^{-1}$, (detection limit of the conductometer) the regeneration process was succeed.

\section{Result and discussion \\ 4.1 Determination of LEP ${ }_{w}$ value of hollow fiber module}

Figure 11. shows the experimental results of $\mathrm{LEP}_{w}$ measurement for the membrane MD $020 \mathrm{CP} 2 \mathrm{~N}$ using the experimental set-up explained in Sect. 3.1.1. (see Figure 6.). It can be well observed that the applied pressure difference resulted a sharp increase in liquid flux once $\mathrm{LEP}_{\mathrm{W}}$ was reached. This point indicated the "flooding" event of the membrane pores. At 0.97 bar transmembrane pressure difference, a liquid flux of $0.62 \mathrm{kgm}^{-2} \mathrm{~h}^{-1}$ was observed. This event was also determined precisely by conductometry since a rapid increase in conductivity could be measured at the respective applied pressure difference. Compare to the value 1.40 bar suggested by the manufacturer (Table 1), 0.97 bar poses a great difference. The difference could origin the LEP measurement technique itself. Other explanation may be that the tested membrane already has been applied for other purposes and these applications could be effect on the structure of the membrane thus the characteristic of the pores and the membrane structure could be changed.

Subsequent to the $\mathrm{LEP}_{\mathrm{w}}$ measurement, hysteresis curve was determined by measuring liquid permeate flux by changing the applied pressure. Figure 12. shows the liquid flux data as a function of transmembrane pressure difference in one graph. 
As expected, a linear relationship $\left(\mathrm{R}^{2}=0.9817\right)$ was found between the applied pressure and the liquid flux of the wetted membrane. A water permeability of $2867 \mathrm{kgh}^{-1} \mathrm{~m}^{-2} \mathrm{bar}^{-1}$ was measured.

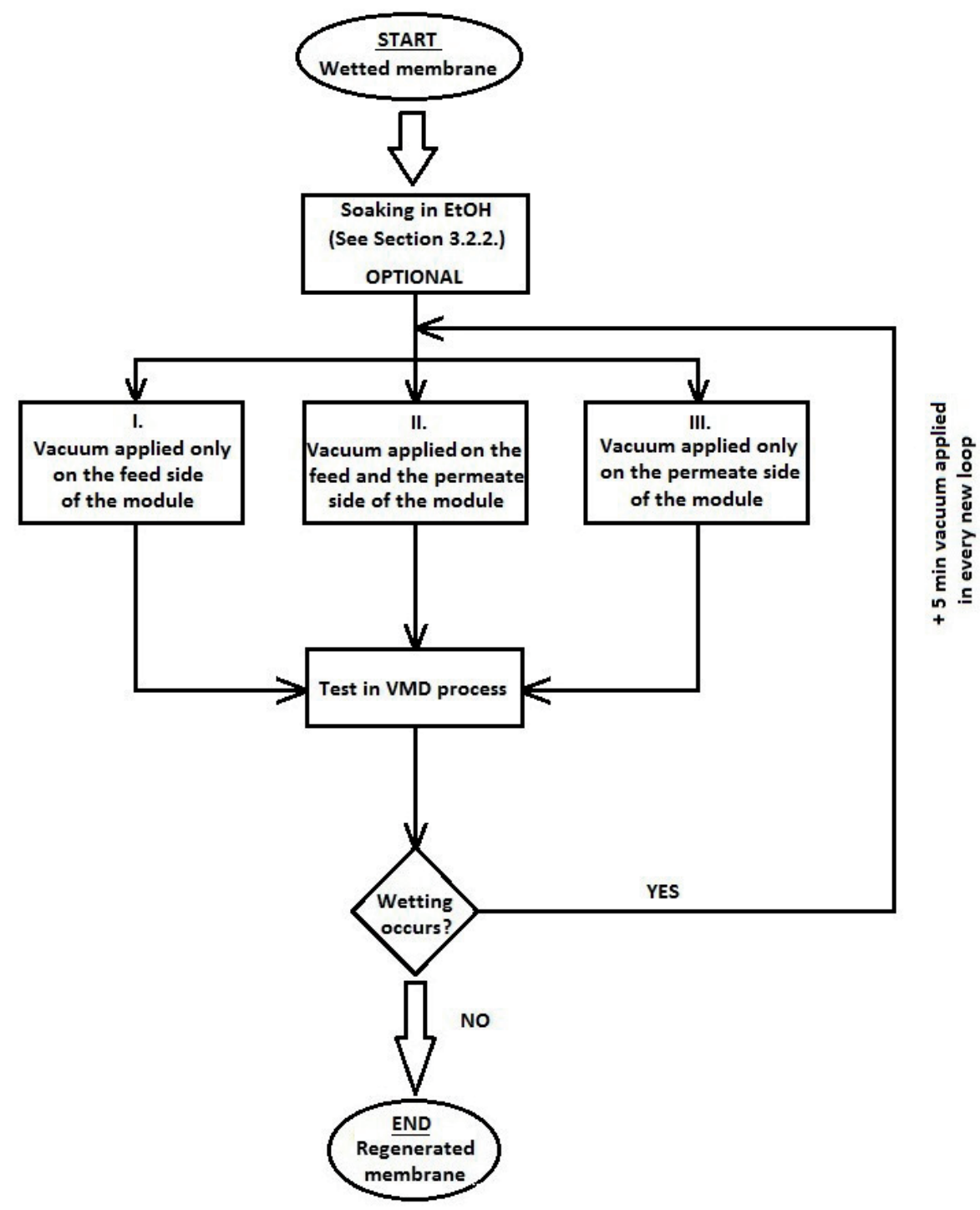

Fig. 10. Experimental plan for regenerating membranes using vacuum.

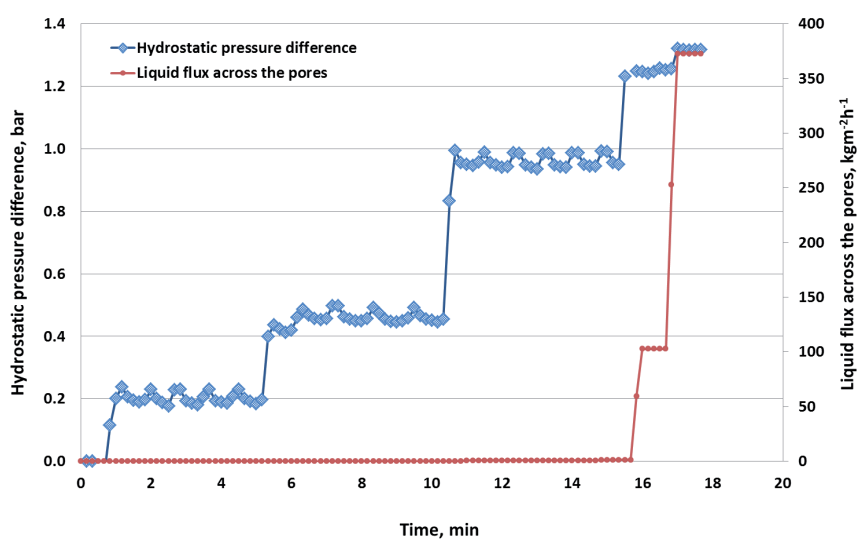

Fig. 11. Liquid flux through the membrane (MD 020 CP $2 \mathrm{~N}$ hollow-fiber membrane (Microdyn-Nadir GmbH, Wiesbaden, Germany)).

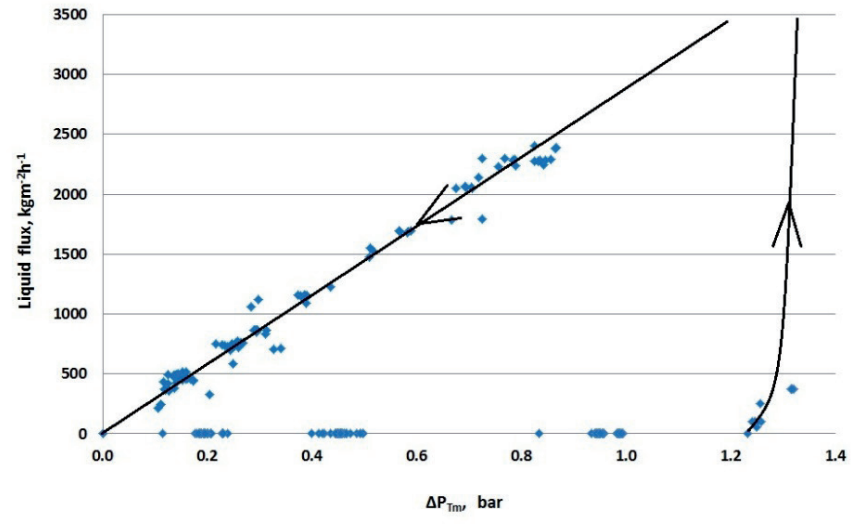

Fig. 12. Hysteresis of hollow fiber membrane module during the wetting (MD 020 CP $2 \mathrm{~N}$ hollow-fiber membrane (Microdyn-Nadir GmbH, Wiesbaden, Germany)). 


\subsection{Identifying of $\mathrm{LEP}_{\mathrm{w}}$ value of}

\section{flat sheet membranes with static method}

In case of the Durapore ${ }^{\mathrm{TM}}$ GVPH flat sheet membrane (Merck Millipore Inc., Billerica, USA), three consecutive measurements were carried out using the procedure explained in Sect. 3.1.2. Each measurement a new membrane disk was used. Feed-side pressure was raised stepwise until a moving meniscus appeared in the permeate tube. The value is identified as $2.37 \pm 0.025$ bar at room temperature. Compare to 2.04/ $2.29 \pm 0.03$ bar values suggested by the manufacturer and open literature data (Table 1), the measured value $2.37 \pm 0.025$ bar is an acceptable result. The difference could origin the LEP measurement technique itself.

\subsection{Wetting of flat sheet membranes with dynamic method}

Figure 13. shows the experimental results of $\operatorname{LEP}_{w}$ measurement with the dynamic method using the flat sheet membrane. At 1.90 bar transmembrane pressure difference, a sudden increase in the flux value can be observed. However this value is a bit less compare to the values $2.04 / 2.29 \pm 0.03$ suggested by the manufacturer and the relevant literature data (Table 1). The difference could origin the LEP measurement technique itself.

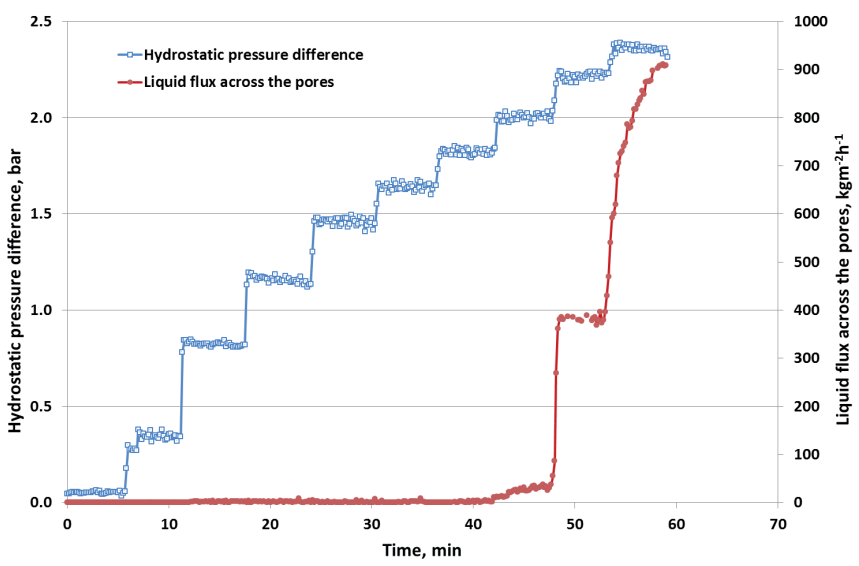

Fig. 13. Liquid flux through Durapore ${ }^{\mathrm{TM}} \mathrm{GVPH}$ flat sheet membrane (Merck Millipore Inc., Billerica, USA).

Based on Figure 13. at hydrostatic pressure difference 0.8 bar very low, but appreciable flux values can be noticed (around $0.2 \mathrm{kgh}^{-1} \mathrm{~m}^{-2}$ ). These values actually origin from the vibration of the tubes generated by the vacuum pump and recorded by the digital balance. Until the 1.90 bar no liquid stream was detected at the permeate side.

Figure 14. illustrates the hysteresis phenomenon. The water permeability of wetted membrane was calculated from the liquid flux vs. transmembrane pressure data, and found to be $500 \mathrm{kgh}^{-1} \mathrm{~m}^{-2} \mathrm{bar}^{-1}\left(\mathrm{R}^{2}=0.7595\right)$.

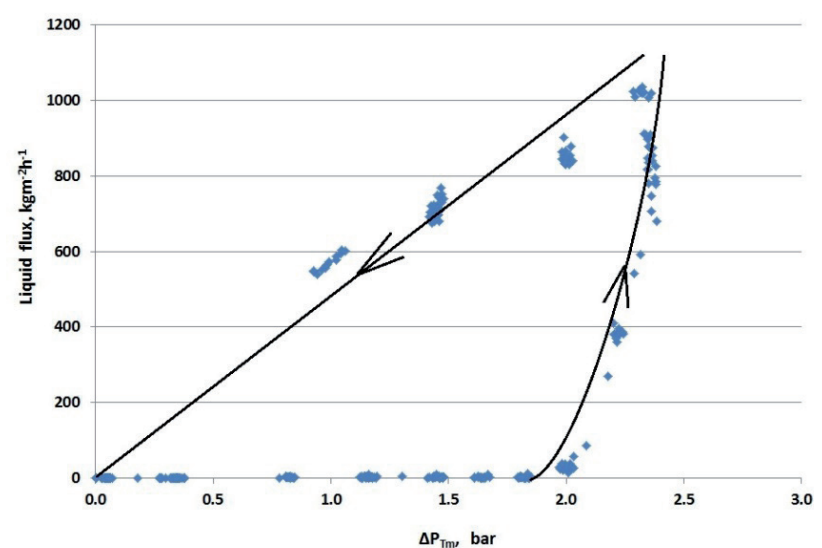

Fig. 14. Hysteresis curve of Durapore ${ }^{\mathrm{TM}} \mathrm{GVPH}$ flat sheet membrane (Merck Millipore Inc, Billerica, USA).

It is very common to indicate the $\mathrm{LEP}_{\mathrm{w}}$ value measured with the static measurement when evaluating the hydrophobic characteristics of the membrane material and its applicability for MD. It is important to note, however, that our dynamic method resulted in a lower $\mathrm{LEP}_{\mathrm{w}}$ value than the static method (2.37 bar vs 1.90 bar). It indicates that the mode of operation (i.e. the hydrodynamic conditions and the distillate-side vacuum formation) may influence the wetting properties of the membrane. In this context, the LEP value measured in VMD configuration likely depicts a more realistic picture about wetting phenomenon occurring in practical MD systems.

\subsection{Regeneration based on solvent evaporation at elevated temperature}

The MD $020 \mathrm{CP} 2 \mathrm{~N}$ hollow fiber membrane was regenerated by ethanol treatment and consecutive solvent evaporation as explained in Sect. 3.2.1. Then, it was tested in DCMD mode of operation. No leakage of salts through the regenerated membrane was found under the given process condition, conductivity of permeate was less than $0.01 \mathrm{mScm}^{-1}$ (lowest displayable value of the measuring range of the conductometer) proving that regeneration was successful.

Regeneration was also carried out without ethanol soaking. After 48 hours of drying in oven at $50^{\circ} \mathrm{C}$, the membrane was tested in a usual DCMD configuration. Slight leakage of salts through the regenerated membrane was found $\left(0.03 \mathrm{mScm}^{-1}\right.$ at $24.7^{\circ} \mathrm{C}$ ) under the given process condition, proving that regeneration was not totally successful. Repeated measurements with varying drying times showed that the regeneration is not feasible.

In case of the Durapore ${ }^{\mathrm{TM}} \mathrm{GVPH}$ membrane, the module was disassembled; the wetted membrane discs was removed from the equipment, treated with ethanol, and placed in the oven. To recover the hydrophobic characteristics of the membrane, a 48 hour drying procedure was applied at $50^{\circ} \mathrm{C}$. VMD configuration 
was used for testing MD performance of regenerated membranes. No leakage of salts through the regenerated membrane was found under the given process condition, conductivity of permeate was less than $0.01 \mathrm{mScm}^{-1}$ (under the detection limit of the conductometer) proving that regeneration was successful.

Tests were also carried out without ethanol soaking. After 48 hours drying procedure in oven at $50^{\circ} \mathrm{C}$, the dried membranes were tested in a usual VMD configuration. No leakage of salts through the regenerated membrane was found under the given process condition, conductivity of permeate was less than $0.01 \mathrm{mScm}^{-1}$ (under the detection limit of the conductometer) proving that regeneration was successful.

Based on our results, it can be pointed out that MD $020 \mathrm{CP}$ $2 \mathrm{~N}$ hollow fiber membrane can only be successfully regenerated under the tested conditions when soaking procedure using ethanol is applied prior to solvent evaporation in the oven. In contrast, the regeneration of the Durapore ${ }^{\mathrm{TM}} \mathrm{GVPH}$ flat sheet membranes using procedures - with and without ethanol treatment - was successful.

\subsection{Regeneration using vacuum}

None of the procedures shown in Figure 10 have been found to be effective in regenerating the MD $020 \mathrm{CP} 2 \mathrm{~N}$ membrane made of PP with useful membrane area $0.1 \mathrm{~m}^{2}$. Irrespectively of duration of treatment (up to 5 hour) and the direction of suction (feed-side, distillate-side, or both), the hydrophobic characteristics of the membrane cannot be recovered. Also, ethanol treatment is proved to be inefficient. Further investigations are required to find appropriate settings (e.g. using warm dry air) of the regeneration procedure.

Regeneration of the Durapore ${ }^{\mathrm{TM}}$ GVPH membranes with $0.00444 \mathrm{~m}^{2}$ useful membrane area made of PVDF was successful using 1.5 hour vacuum treatment based on suction at both feed and distillate side. No leakage of salts through the regenerated membrane was found under the given process condition, conductivity of permeate was less than $0.01 \mathrm{mScm}^{-1}$ (lowest displayable value of the measuring range of the conductometer) proving that regeneration was successful. Surprisingly, regeneration failed in all cases when ethanol treatment is used prior to vacuum treatment. Even 5 hour vacuum tests failed after ethanol treatments.

\section{Conclusions}

Wetting of membrane pores by liquid streams (i.e. the loss of hydrophobic characteristics of membranes) is a crucial issue in MD treatment. In the present work, the theoretical background of wetting phenomenon in MD as well as the different experimental techniques of $\mathrm{LEP}_{\mathrm{w}}$ measurement provided in the open literature have been summarized. The state-of-the-art review is accompanied with experimental data obtained from LEP measurements and regeneration tests. Two commercial hydrophobic microporous membranes, MD $020 \mathrm{CP} 2 \mathrm{~N}$ hollow-fiber membrane (Microdyn-Nadir GmbH, Wiesbaden, Germany) and Durapore $^{\mathrm{TM}}$ GVPH flat sheet membrane (Merck Millipore Inc., Billerica, USA), were examined in our lab.

The LEP ${ }_{w}$ value of MD 020 CP 2N hollow-fiber membrane (Microdyn-Nadir GmbH, Wiesbaden, Germany) in direct contact membrane distillation configuration was found to be 0.97 bar. The $\mathrm{LEP}_{\mathrm{w}}$ value Durapore ${ }^{\mathrm{TM}} \mathrm{GVPH}$ flat sheet membrane (Merck Millipore Inc., Billerica, USA) was also investigated using static and dynamic methods. The static method resulted a greater $\mathrm{LEP}_{\mathrm{w}}$ value $(2.37 \pm 0.025$ bar) than the dynamic method (1.90 bar). The result of the static method is in good agreement with the data provided by the manufacturer and values found in the literature (2.04 - 2.29 bar). Our novel dynamic measurement, however, indicates that $\mathrm{LEP}_{\mathrm{w}}$ value depends on the MD configuration (i.e. hydrodynamics conditions and distillate-side vacuum), thus, its actual value might be smaller under true process conditions.

Regeneration of wetted membranes is an important issue that is far less investigated in the literature. In this work, two different regeneration methods were investigated to recover the hydrophobic characteristics of the wetted membranes. The first method employs elevated temperature to regenerate the wetted membranes, while the second method uses vacuum sucking in various ways at ambient temperature for the same purpose. Optional treatment with a $96 \mathrm{v} / \mathrm{v} \%$ ethanol solution was also employed to increase the performance of the regeneration methods

It was found that solvent evaporation in laboratory oven is an effective method to recover the polypropylene hollowfiber membrane (MD $020 \mathrm{CP} 2 \mathrm{~N}$ by Microdyn-Nadir GmbH, Wiesbaden, Germany) if ethanol soaking prior to evaporation takes place. As for the Durapore ${ }^{\mathrm{TM}} \mathrm{GVPH}$ flat sheet membranes (Merck Millipore Inc., Billerica, USA), regeneration processes using elevated temperature in the oven with and without ethanol treatment were successful

The conventional regeneration method using evaporation procedure at elevated temperatures is time-consuming and has limited applicability in industrial settings since it ideally requires disassembling the modules before drying the membranes sheets. In our lab, we have tested the effectiveness of regeneration applying vacuum in various configurations. Employing a vacuum pump has been proved to be effective for recovering the hydrophobic characteristics of the PVDF membranes in the tested flat-sheet module (Durapore ${ }^{\mathrm{TM}} \mathrm{GVPH}$ from Merck Millipore Inc., US), however, it failed in case of the hollow-fiber module (MD020CP2N from Microdyn-Nadir $\mathrm{GmbH}$, Germany). Further investigations are required to find appropriate regeneration techniques that can be implemented in MD practice at large-scale. 


\section{References}

1 Godino M. P., Peña L., Rincón C., Mengual J. I., Water production from brines by membrane distillation. Desalination, 108 (1-3), pp. 91-97, (1996).

DOI: 10.1016/S0011-9164(97)00013-1

2 Guillén-Burrieza E., Blanco J., Zaragoza G., Alarcón D. C., Palenzuela P., Ibarra M., Gernjak W., Experimental analysis of an air gap membrane distillation solar desalination pilot system. Journal of Membrane Science, 379 (1-2), pp. 386-396, (2011).

DOI: 10.1016/j.memsci.2011.06.009

3 Banat F. A., Simandl J., Removal of benzene traces from contaminated water by vacuum membrane distillation. Chemical Engineering Science, 51 (8), pp. 1257-1265, (1995). DOI: 10.1016/0009-2509(95)00365-7

4 Pal P., Manna A. K., Removal of arsenic from contaminated groundwater by solar-driven membrane distillation using three different commercial membranes. Water Research, 44 (19), pp. 5750-5760, (2010). DOI: $\underline{10.1016 / \text { j.watres.2010.05.031 }}$

5 Gryta M., Karakulski K., The application of membrane distillation for the concentration of oil-water emulsions. Desalination, 121 (1), pp. 23-29, (1999).

DOI: 10.1016/S0011-9164(99)00004-1

6 Lewandowicz G., Białas W., Marczewski B., Szymanowska D., Application of membrane distillation for ethanol recovery during fuel ethanol production. Journal of Membrane Science, 375 (1-2), pp. 212-219, (2011).

DOI: $\underline{10.1016 / \text { j.memsci.2011.03.045 }}$

7 Koroknai B., Kiss K., Gubicza L., Bélafi-Bakó K., Coupled operation of membrane distillation and osmotic evaporation in fruit juice concentration. Desalination, 200 (1-3), pp. 526-527, (2006).

DOI: 10.1016/j.desal.2006.03.422

8 Gethard K., Mitra S., Membrane distillation as an online concentration technique: application to the determination of pharmaceutical residues in natural waters. Analytical and Bioanalytical Chemistry, 400 (2), pp. 571-575, (2011).

DOI: $10.1007 / \mathrm{s} 00216-011-4733-9$

9 Susanto H., Towards practical implementations of membrane distillation. Chemical Engineering and Processing: Process Intensification, 50 (2), pp. 139-150, (2011). DOI: $10.1016 /$ j.cep.2010.12.008

10 Lawson K. W., Lloyd D. R., Review: Membrane distillation. Journal of Membrane Science, 124 (1), pp. 1-25, (1997). DOI: 10.1016/S0376-7388(96)00236-0

11 Essalhi M., Khayet M., Surface segregation of fluorinated modifying macromolecule for hydrophobic/hydrophilic membrane preparation and application in air gap and direct contact membrane distillation. Journal of Membrane Science, 417-418, pp. 163-173, (2012). DOI: $10.1016 /$ i.memsci.2012.06.028

12 Wei X., Zhao B., Li X. M., Wang Z., He B.Q,, He T., Jiang B., CF4 plasma surface modification of asymmetric hydrophilic polyethersulfone membranes for direct contact membrane distillation. Journal of Membrane Science, 407-408, pp. 164-175, (2012). DOI: 10.1016/j.memsci.2012.03.031
13 Kim H., Noh K., Choi C., Khamwannah J., Villwock D., Jin S., Extreme superomniphobicity of multiwalled $8 \mathrm{~nm}$ TiO2 nanotubes. Langmuir, 27 (16), pp. 10191-10196, (2011).

DOI: $\underline{10.1021 / 1 \mathrm{a} 2014978}$

14 Franken A.C. M., Nolten J. A. M., Mulder M. H. V., Bargeman D., Smolders C. A., Wetting criteria for the applicability of membrane distillation. Journal of Membrane Science, 33 (3), pp. 315-328, (1987). DOI: $10.1016 / \mathrm{S} 0376-7388(00) 80288-4$

15 Kim B. S., Harriott P., Critical entry pressure for liquids in hydrophobic membranes. Journal of Colloid and Interface Science, 115 (1), pp. 1-8, (1987). DOI: $10.1016 / 0021-9797(87) 90002-6$

16 Zha F. F., Fane A. G., Fell C. J. D., Schofield R. W., Critical displacement pressure of a supported liquid membran. Journal of Membrane Science, 75 (1-2), pp. 69-80, (1992). DOI: $10.1016 / 0376-7388(92) 80007-7$

17 Garcia-Payo M. C., Izquierdo-Gil M. A., Fernández-Pineda C., Wetting Study of Hydrophobic Membranes via Liquid Entry Pressure Measurements with Aqueous Alcohol Solutions. Journal of Colloid and Interface Science, 230 (2), pp. 420-431, (2000).

DOI: $10.1006 /$ jcis. 2000.7106

18 Khemakhem S., Amar R. B., Modification of Tunisian clay membrane surface by silane grafting: Application for desalination with Air Gap Membrane Distillation process. Colloids and Surfaces A: Physicochemical and Engineering Aspects, 387 (1-3), pp. 79-85, (2011). DOI: $10.1016 /$ j.colsurfa.2011.07.033

19 Khayet M., Velázquez A., Mengual J. I., Modelling mass transport through a porous partition: Effect of pore size distribution. Journal of Non-Equilibrium Thermodynamics, 29 (3), pp. 279-299, (2004). DOI: $10.1515 /$ JNETDY.2004.055

20 Izquierdo-Gil M. A., Garcia-Payo M. C., Fernández-Pined C., Air gap membrane distillation of sucrose aqueous solution. Journal of Membrane Science, 155 (2), pp. 291-307, (1999). DOI: $10.1016 / \mathrm{S} 0376-7388(98) 00323-8$

21 Smolder K., Franken A. C. M., Terminology for Membrane Distillation. Desalination, 72 (3), (1989), pp. 249-262. DOI: $10.1016 / 0011-9164(89) 80010-4$

22 Khayet M., Matsuura T., Preparation and Characterization of Polyvinylidene Fluoride Membranes for Membrane Distillation. Industrial \& Engineering Chemistry Research, 40 (24), pp. 5710-5718, (2001). DOI: $10.1021 / \mathrm{ie} 010553 \mathrm{y}$

23 He K., Hwang H. J., Moon I. S., Air gap membrane distillation on the different types of membrane. Korean Journal of Chemical Engineering, 28 (3), pp. 770-777, (2011). DOI: $\underline{10.1007 / \mathrm{s} 11814-010-0415-0}$

24 Peña L., Ortiz de Zárate J. M., Mengual J. I., Steady states in membrane distillation: Influence of membrane wetting. Journal of the Chemical Society, Faraday Transactions, 89, pp. 4333-4338, (1993). DOI: $\underline{10.1039 / F T 9938904333}$ 